Artículo de reflexión derivado de investigación
Revista Colombiana de Educación, N. 69 Segundo semestre de 2015 Bogotá, Colombia.

\section{La interculturalidad: ¿principio o fin de la utopía?}

//Interculturality: Utopia's Start or End?

\section{da utopia?}

Recibido: 19/12/2014 Evaluado: 28/03/2015 25/03/2015 $03 / 03 / 2015$

\begin{abstract}
Magíster en Psicología Social y Comunitaria, Pontificia Universidad Javeriana. Profesora e investigadora del Departamento de Estudios Interculturales de la Universidad del Cauca. Popayán, Colombia. elcastil@gmail.com

Doctora en Educación, Universidad Pedagógica Nacional. Profesora de la Universidad Pedagógica Nacional. Bogotá Colombia.sguido@pedagogica.edu.co
\end{abstract}

\title{
Resumen
}

La interculturalidad, como noción reciente en el campo de la educación, representa un complejo entramado de significados, apropiaciones y sentidos. Sus orígenes son diversos e incluso contradictorios, según el lugar de producción de sus definiciones más precisas. Sus usos en el plano de las políticas públicas y las agendas globales educativas son un verdadero calidoscopio en el cual figuran tensiones y convergencias propias del multiculturalismo del fin del siglo XX. En el terreno de las luchas y el activismo de los denominados movimientos étnicos, esta noción adquiere relevancia ideológica para confrontar los asuntos del poder, la exclusión y la subalternidad. Este artículo pretende ofrecer una mirada panorámica en torno a estos asuntos en dos planos específicos. Por una parte, sobre los recorridos de lo intercultural en su configuración como objeto de conceptualizaciones y teorizaciones de los saberes expertos en educación mundial y continental. Por otra parte, en el contexto de Colombia, como una posibilidad de visibilizar las dinámicas y las fuerzas que determinan el curso que el enfoque de lo intercultural toma en un momento histórico determinado. Finalmente se presentan algunos problemas fundamentales para superar cierta "ingenuidad" en el debate sobre la interculturalidad en América Latina.

\section{Abstract}

Interculturality, a new notion in education, is a complex web of meanings, appropriations and senses. Its origins are diverse and even contradictory, depending on the place of production of their more accurate definitions. Its uses in terms of public policy and global educational agendas are a real kaleidoscope including tensions and convergences typical of the late twentieth century multiculturalism. In the field of struggles and activism of so-called ethnic movements, this notion acquires ideological relevance to confront issues of power, exclusion and subordination. This article pretends to provide an overview about these issues, and on two specific levels. On the one hand, on the journeys of interculturality in its configuration as an object of conceptualizations and theories by experts on global and continental education. On the other hand, in the Colombian context, as a possibility to visualize the dynamics and forces that determine the focus of interculturality at a given time in history. Finally, we present some problems that we consider fundamental to overcome certain "naivety" in the debate over interculturality in Latin America.

\section{Palabras clave}

Interculturalidad, educación, etnicidad, Integracionismo, nación, políticas educativas, derechos culturales

\section{Keywords}

Interculturality, education, ethnicity, Integrationism, Nation, educational politics, cultural rights

\section{Palavras chave}

Interculturalidade, educação, etnicidade, Integração, nação, políticas educativas, direitos culturais 


\title{
Resumo
}

\begin{abstract}
A interculturalidade, como noção recente no campo da educação, representa uma complexa rede de significados, apropriações e sentidos. Seus origens são diversos e inclusive contraditórios, conforme o lugar de produção de seus definições mais precisas. Seus usos no plano das políticas públicas e as agendas globais educativas são um verdadeiro calidoscópio no qual figuram tensões e convergências próprias do multiculturalismo de finais do século XX. No terreno das lutas e o ativismo dos denominados movimentos étnicos, esta noção adquire relevância ideológica para confrontar os assuntos do poder, a exclusão e a subalternidade. Por tanto, este artigo pretende oferecer uma olhada panorâmica em torno a estes assuntos e em dois planos específicos. Por um lado, sobre os percursos do intercultural em sua configuração como objeto de conceptualizações e teorizações dos saberes especializados em educação mundial e continental. Por outro lado, no contexto colombiano, como uma possibilidade de visibilizar as dinâmicas e as forças que determinam o curso que o enfoque do intercultural assumi em um momento histórico determinado. Finalmente, apresentamos alguns problemas que consideramos fundamentais para superar certa "ingenuidade" no debate sobre a interculturalidade na América Latina.
\end{abstract}

Se tiene derecho a la igualdad si la diferencia nos reduce; se tiene derecho a la diferencia si la igualdad nos resta características. Boaventura de Sousa Santos

\section{Los orígenes diversos de la interculturalidad}

El fin del siglo XX vino recargado de luchas por los derechos culturales. Fenómenos como el debilitamiento de los Estados nacionales, el auge de las comunidades étnicas, la emergencia de una noción de cultura alejada del universalismo y más cercana a la singularidad y la diversidad social; la ola migratoria mundial, y la apabullante globalización económica y mediática son, entre muchos otros, situaciones que acentuaron el asunto del reconocimiento, la diferencia cultural y sus derechos, en un marcado ambiente de desigualdades, inequidades, discriminaciones y exclusiones acumuladas durante los últimos cien años.

En este contexto y como marco de acción política surgen conceptos como los de multiculturalidad e interculturalidad. Sobre el primero solo cabe decir que lo multicultural ha sido un adjetivo ligado a la separación de grupos con sus diferencias culturales (Demorgon, 2010), sin preocuparse por las relaciones entre estos. Este se ha constituido en un hecho social e histórico, que en algunas ocasiones ha llevado a una regulación institucional que se materializa en acciones políticas y jurídicas de los Estados (Castillo, 2005; Muñoz, 2002; Rojas, 2005). Su implementación ha presentado diferentes problemas, se encuentra 
entre la construcción de una sociedad multicultural y la lucha contra la exclusión y la desigualdad; se reconoce la diferencia pero la desigualdad social, política y económica continúa. Así mismo, se favorecen comportamientos de tolerancia, diálogo, respeto de los derechos humanos, de la democracia y de la inclusión, pero desde una jerarquización dominado-dominante (Dussel, 2005) o en palabras de Hall (2003), desde un punto de vista de un observador ideal, una autoridad que supervisa los derechos (e ideas) éticos de la perspectiva liberal, desde una "súper posición". Finalmente, se ha considerado como un retroceso para las luchas socio-históricas y políticas de los movimientos sociales en el sentido de constituirse en un sedimento burocrático que borra el conflicto político y mantiene las distancias propias que imposibilitan un diálogo genuino.

La interculturalidad como perspectiva surge en América Latina principalmente desde las comunidades indígenas, tal como lo plantea el mexicano Héctor Muñoz:

Las nociones de interculturalidad y educación intercultural aparecen en la mayoría de las naciones latinoamericanas en el último cuarto del siglo XX. Específicamente, forman parte de la retórica innovadora de los pioneros proyectos experimentales de educación bilingüe (Puno, Perú andino y Cuenca, Ecuador) y de los primeros sistemas escolares subordinados en la década de los años ochenta en México, pues bien de esta época provienen los primeros $y$ ambiguos intentos de pedagogizar el multiculturalismo. (2002, p. 1)

Visto de este modo, la interculturalidad requiere de negociaciones para lograr nuevas prácticas, como la puesta en común de valores, perspectivas, ideologías e intereses y "en este espacio fronterizo de relación y negociación también se construyen y emergen nuevas estrategias, expresiones, iniciativas, sentidos y prácticas interculturales que desafían la homogeneidad, el control cultural, y la hegemonía de la cultura dominante" (Homi Bhaba, 1994, p. 10). En un sentido diferente a la multiculturalidad, más que un concepto descriptivo la interculturalidad se convierte en un proyecto político, social, epistémico y ético dirigido a la transformación cultural y socio-histórica. Esta hace entonces referencia al cruzamiento, la relación, el contacto, el mestizaje, la confrontación, la negociación, la intersección, interpenetración o interestructuración positiva de culturas (Manco, 2000).

Aunque la interculturalidad aparece como una nueva forma de relacionarse, como un discurso político de resistencia y reivindicación 
cultural de algunos grupos poblacionales, es importante mencionar que sus usos políticos o sociales no han sido homogéneos. La noción la interculturalidad ha estado asociada en sus orígenes a un sentido contra-hegemónico (Dietz, 2012), pero igualmente ha sido funcional a los discursos globales gubernamentales y de organismos internacionales. Por esta razón su trámite como proyecto emancipatorio en las posturas de los movimientos sociales requiere de esta diferenciación en su análisis.

Garcés (2007) propone considerar diferentes tendencias para analizar el término interculturalidad. La más generalizada lo asocia con la idea de un encuentro de culturas que puede dar paso a relaciones en función de horizontalidad y verticalidad. Otra perspectiva la localiza en el ámbito de las actitudes que sostienen un relacionamiento intercultural. Y la última se concentra en el reconocimiento de la diversidad existente, vista desde una óptica de la cultura dominante y nacional. A estas posturas subyace una serie de concepciones fijas y esencialistas sobre la cultura. Ahora bien, la interculturalidad, vista desde una concepción crítica de lo cultural, se plantea como medio y fin de nuevos relacionamientos sociales, cruzados por la diversidad y el conflicto.

Demorgon (2010) plantea la tendencia de una interculturalidad de ajuste, noción que implica pensar las diferencias en la universalidad, lo que estimula la búsqueda y la coexistencia de diversidades culturales, singulares de personas, de grupos y de sociedades. Esta surge durante la segunda mitad del siglo XX en dominios como los de las relaciones internacionales, las culturas empresariales, las migraciones, las creaciones estéticas y mediáticas, y la universalización de los intercambios. Lo intercultural es visto como un conjunto de oportunidades propias del nuevo orden cultural global de la sociedad de la información. El autor plantea una interculturalidad voluntaria, que se establece a partir de culturas adquiridas, en las cuales los miembros de unas y otras consiguen adaptarse entre sí. De ella se preocupan trabajadores sociales, gerentes y pedagogos que propenden por comprenderse, cooperar en beneficio del éxito de la empresa o de la paz civil en los barrios. Puede también conllevar a innovaciones, invenciones y luego engendrar culturas nuevas.

Finalmente la interculturalidad de génesis se preocupa por el origen cultural de las sociedades y de sus culturas. Parte del hecho de que la violencia, como fuente de cultura, no puede ser ignorada. Tiene el mérito de recalcar las transformaciones recíprocas que en efecto pueden ser asimétricas. La interculturación 
es la verdadera noción operatoria central de los estudios históricos y sociológicos, ya que no solo permite establecer claramente entre quién y quién, sino también entre qué y qué existe interculturación.

En síntesis, se podría hablar de una interculturalidad funcional al sistema que, como estrategia, utiliza la interculturalidad institucional y una interculturalidad crítica, y que, como proyecto político, ético y epistémico, propende por la intervención en estructuras, instituciones y mentalidades (Walsh, 2009). Este panorama sobre el concepto y uso de la interculturalidad tiene como fin mostrar algunas de sus aristas para declarar la necesidad de analizar los actores que se interesan en la misma, sus intereses, necesidades y proyecciones con el fin de comprender su tránsito en el campo educativo.

Conviene analizar algunos de los principales modelos prevalecientes en las políticas y prácticas educativas que en contextos de diferencia cultural se reconocen en el horizonte de la "interculturalidad". Se trata de enfoques que transitan por versiones asimilacionistas, integracionistas, multiculturalistas e interculturalistas. Para efectos de orden histórico y conceptual podemos retomar de manera general las principales aportaciones de autores como Dietz, 2013; Duschatzky \& Skliar, 2001; Fernández \& Muñoz, 1998; García, Pulido \& Montes, 1998; Fleuri, 2006; y Meunier, 2007, para consolidar cuatro grandes momentos y enfoques en este trasegar de lo intercultural. Dichos modelos han estado relacionados mayoritariamente en el campo educativo con poblaciones migrantes.

\section{El modelo asimilacionista}

No asume las diferencias culturales para la enseñanza. En este sentido, para los estudiantes foráneos se propone una enseñanza de los programas educativos nacionales, haciendo uso de estrategias pedagógicas compensatorias con desconocimiento de las familias y de sus valores. En general se podría decir que las diferencias culturales se perciben como un obstáculo para la integración escolar.

Su base es la hipótesis déficitdeprivación cultural, mediante la cual se relaciona el fracaso escolar con la pertenencia sociocultural. Para Meunier (2007) "Le modèle de l'assimilation repose sur l'hypothèse d'un 'déficit culturel' des élèves $d$ 'origine étrangère ou appartenant à des minorités ethniques. II postule un lien de cause à effet entre leur échec scolaire et leur milieu d'appartenance socio-culturel"1.

Así mismo, este modelo se sustenta en la asimilación cultural que propende por el abandono de la cultura de origen, entendida en

El modelo de asimilación reposa sobre la hipótesis de un déficit cultural de los estudiantes de origen extranjero o perteneciente a minorías étnicas. Este postula una relación de causa- efecto entre el fracaso escolar y el medio de pertenencia sociocultural (traducción libre de las autoras). 
algunos sentidos como aculturación. Al respecto afirma Fleuri (2006) que el problema del encuentro y del conflicto entre culturas es antiguo y que ha sido enfrentado y resuelto generalmente a partir de perspectivas etnocéntricas, que pretenden imponer el propio punto de vista como el único válido. Se da de esta manera un proceso de asimilación cultural recíproca, en el que cada uno olvida sus propias raíces. Reafirma esta idea Meunier (2007) al mencionar: "L'assimilation représente donc l'une des modalités du processus d'acculturation qui donne lieu à l'abandon ou à la dis-solution de la culture d'origine et à l'adoption de nouveaux modèles culturels, généralement ceux de la culture d'adoption" (Abdallah-Pretceille, 2001, p. 15).

Como consecuencias de la implementación de este modelo se sigue reproduciendo la desigualdad social y la marginalización, pero a su vez se encuentra la defensa de culturas originarias por parte de grupos étnicos. Para Fleuri (2006) las diferencias étnicas y culturales, aparentemente negadas, de hecho no desaparecían, sino que se transformaban en desigualdades sociales y en procesos de marginalización. Y, por reacción, los grupos étnicos subalternos buscaban encontrar nueva cohesión, polarizando las fuerzas en torno a la defensa de sus identidades originarias.

Así, mediante el modelo asimilacionista las prácticas educativas responden a la función, como instituciones del Estado, de construir y hacer aceptar la definición de una cultura que representa a una comunidad homogénea, le da sentido a la vida de todos sus miembros y a la identidad nacional, pero "eliminando" la diferencia y relegándola al ámbito privado.

\section{El modelo integracionista}

Tiene como fin democratizar, modernizar y desarrollar los Estados. Forma en competencias para la tolerancia, el respeto y la inclusión. Fleuri (2006) afirma que los trabajos que intentaron promover la integración suponen la necesidad de dar espacio a la diversidad para crear un clima de respeto mutuo y tolerancia. En este se admiten elementos de culturas originarias y se favorece una participación igualitaria de los grupos minoritarios en instituciones sociales, económicas y políticas. De acuerdo con este autor, se comenzaron a admitir elementos de las culturas de origen para garantizar

2 La asimilación representa uno de los procesos de aculturación que da lugar al abandono o a la disolución de la cultura originaria y a la adopción de nuevos modelos culturales, generalmente los de la cultura de adopción (traducción libre de las autoras). 
mayor pluralismo. Se buscaba la integración, es decir, la asimilación en la cultura anfitriona, sin dejar de reconocer las diferencias.

Se da valor a las diferencias y se propende por la identificación de las semejanzas. El modelo integracionista promueve el trabajo en grupo y hace conciencia sobre la formación de prejuicios y estereotipos, como lo afirma Meunier (2007) "Il n'est donc plus question d'assimiler les différents groupes à la culture dominante, mais de provoquer chez les élèves des sentiments positifs de l'unité nationale"'3. Una de las consecuencias de la implementación de este modelo ha sido el no precisar el estatus de las minorías en la sociedad, es decir, se reconoce la diversidad cultural pero no se tocan las estructuras sociales, se podría decir que se reconoce la diferencia pero no se trabaja por poner fin a la desigualdad.

\section{El modelo multiculturalista}

Su entrada en el campo educativo es reciente, dado que los modelos anteriores devaluaron otras narrativas, produciendo una escuela disciplinadora y homogenizante. Las diversas formas de acción del multiculturalismo dan cuenta, según Duschatzky y Skliar (2001), de las discrepancias de interpretación existentes acerca de la alteridad, de las representaciones y de las concepciones de cultura

3 No se trata más, entonces, de la pregunta por asimilar los diferentes grupos a la cultura dominante, sino de provocar en los estudiantes sentimientos positivos de la unidad nacional (traducción libre de las autoras). en los proyectos pedagógicos. Esta perspectiva, según Fleuri (2006), configura una propuesta de "educación para la alteridad", enfocada a los derechos del otro, a la igualdad de dignidad y oportunidades; una propuesta democrática amplia que, en el mundo anglosajón (Estados Unidos, Canadá y Gran Bretaña), se define como Multicultural Education $^{4}$, y que en otros países de Europa asume diferentes denominaciones: pedagogía del acogimiento, educación para la diversidad, etc. Estas propuestas tienen como objetivo promover la relación y el respeto entre grupos socioculturales, mediante procesos democráticos y dialógicos. "L'éducation multiculturelle peut être considérée comme une approche basée sur des valeurs et des croyances démocratiques, en affirmant un pluralisme culturel dans des sociétés culturellement diverses et un monde interdépendant"15 (Meunier, 2007).

Su propósito es el de reforzar el respeto y la tolerancia entre grupos mayoritarios y minoritarios, favorecer la confianza en sí mismos y la movilidad social de los grupos minoritarios. Los proyectos multiculturales (aunque la mayoría hayan sido superficiales y folclóricos) se basaban en la filosofía de que la elevación de la autoestima de los niños aumentaría su rendimiento y

\footnotetext{
Educación multicultural.

La educación multicultural puede ser considerada como un enfoque basado en valores y creencias democráticas en afirmación de un pluralismo cultural en sociedades culturalmente diversas y en un mundo interdependiente (traducción libre de las autoras).
} 
la adaptación al contexto escolar (Fleuri, 2006). Con este fin se favorecen los procesos de identificación con la propia cultura y se lucha contra la discriminación y el racismo. En la escuela los profesores deben tener en cuenta los contenidos culturales y la formación en historia, modo de vida y lengua de cada grupo.

Dentro del modelo multiculturalista se pueden encontrar diversas perspectivas: la educación para la diversidad, que se fundamenta en la sociología interaccionista en la cual la cultura es una dinámica de organización de diferencias internas. En esta se transmiten saberes plurales y críticos, aquí la diversidad se entiende como valor educativo y su formación para la diversidad se dirige a todos los estudiantes. Por su parte, la perspectiva de contribuciones étnicas amplía superficialmente el programa escolar, se privilegian para la enseñanza elementos de la cultura material de grupos culturales y la diferencia cultural se celebra en fechas importantes. En la perspectiva antirracista se reflexiona sobre las causas de la discriminación y se hacen campañas contra la misma, se refuerzan el autoconcepto y la identidad a la vez que se estudian las contribuciones de grupos étnicos a la nación. A esta perspectiva se le acusa de ser ideológica y sectaria a causa de la consolidación de estereotipos y representaciones étnicas.

Las consecuencias de este modelo están correspondidas con una relación binaria entre grupos culturales, una correspondencia exacta entre individuo y grupo étnico, conflictos entre mayoría y minoría, lengua oficial y lengua propia, alta y baja cultura, cultura familiar y escolar, regional y central y desconocimiento de procesos de construcción de la diferencia. Su base es la antropología cultural estadounidense, en la cual todas las culturas deben preservarse en su unidad. Políticamente su fundamento es el reconocimiento constitucional, en casi todos los países de América Latina, del carácter multiétnico y pluricultural de sus naciones a partir de los años noventa.

\section{El modelo interculturalista}

Tanto el concepto como la apuesta educativa intercultural surgen en América Latina desde los pueblos indígenas como una forma de desenfocar el trabajo educativo en aspectos lingüísticos y centrarlo en elementos culturales. Sin embargo, para el propósito del artículo hablamos de modelo interculturalista en el sentido amplio, que fue luego cooptado por el discurso de la educación para inmigrantes o proyectos educativos 
nacionales con un enfoque de interculturalidad para todos. Este modelo entonces promueve la formación para una visión de mundo tanto individual como colectiva, está abierto a otras culturas, facilita la reconfiguración y descentración cultural, diferencia sin discriminar y combate el etnocentrismo para la construcción de nuevos esquemas de pensamiento. "L'éducation interculturelle est pensée comme la transmission d'un savoir pluriel et critique, résultant d'interactions, de réciprocités ou plus globalement d'intersubjectivités. Elle s'adresse à tous les élèves, au-delà de leurs différences"6 (Meunier, 2007).

En su práctica educativa se interesa tanto por la cultura construida por el individuo como por los colectivos. Reconoce las dificultades de la interacción cultural y teoriza sobre la complejidad y ambivalencia de las relaciones culturales. Este modelo sobrepasa lo étnico al interesarse también por las relaciones de género y etarias, además de las de clase y raza. Se fundamenta en la identificación de grupos y sus problemas sociales así como en la conquista de sus derechos.

El modelo interculturalista pone en cuestión los sistemas educativos nacionales y la negación de lenguas y de culturas propias y refuerza tanto la identidad como la adquisición de

6 La educación intercultural es pensada como la construcción de un saber plural y crítico resultado de interacciones, reciprocidades o más globalmente de intersubjetividades. Esta se dirige a todos los estudiantes más allá de sus diferencias (traducción libre de las autoras). conocimientos culturales de otros pueblos. "L'objectif de l'éducation interculturelle est alors de faciliter les opérations de décentration et de recadrage résultant de l'altérité pour construire de nouveaux schèmes de pensée non réductibles aux cultures en interaction"7 (Meunier, 2007). En la escuela este modelo propende por un análisis crítico de la diversidad y trabaja por una descentración cultural. Los problemas culturales se analizan desde diferentes perspectivas culturales; se tiene en cuenta el contexto sociocultural de los estudiantes y la heterogeneidad como una norma y no como un déficit, en este sentido se evita asociar la diferencia con el fracaso escolar. Además, se trabaja sobre aprendizajes transversales de conocimientos, prácticas y representaciones.

Sin embargo, y como uno de los principales escollos, seguimos a Meunier (2007) cuando dice que: "L'approche interculturelle est structurée par la tension ou l'équilibre toujours instable entre l'universel et le singulier qui définissent conjointement le sujet"s. Es décir que $A u$ niveau philosophique, elle doit à la fois assurer une version personnelle de la culture fondée sur le pluralisme, mais aussi une version

El objetivo de la educación intercultural es entonces facilitar las operaciones de descentración y reajuste resultado de la alteridad para construir nuevos esquemas de pensamiento no reductibles a las culturas en interacción (traducción libre de las autoras).

8 El enfoque intercultural está estructurado por la tensión o el equilibrio diario e inestable entre lo universal y lo particular que define conjuntamente al sujeto (traducción libre de las autoras) 
collective d'une synthèse pluraliste de l'histoire des différences et des similitudes relatives aux identités nationales. (Dittman, citado en Meunier, 2007) ${ }^{9}$

En la tabla 1 se resumen las características principales de los cuatro modelos.

Los modelos que hemos referido en el anterior apartado permiten analizar las diferencias de enfoques a la hora de poner el acento en el medio o en el fin educativo. Para algunos la interculturalidad es una manera de producir una educación más democrática y centrada en valores liberales como la tolerancia. En otros casos la interculturalidad es vista como un fin, es decir como el horizonte hacia el cual debe avanzar el acto educativo. Existe también un plano en el cual lo intercultural es visto como un ámbito de conocimientos que son intercambiables y accesibles sin que ello ponga en cuestión la posición de los sujetos que representan las diferencias o diversidades en concreto.

Todos estos modelos coexisten y en su práctica educativa corresponden a lo que Zambrano (2006) denomina educación para la diversidad, la cual se debate entre una educación que es el conjunto de educaciones particulares, $y$ otra, que centra sus esfuerzos en articular, enlazar y unir lo distinto, y concertarlo y acoplarlo. Acerca de los contenidos, aparece el problema de vincular núcleos focales (proceso local) y transversales (proceso universal) en los que cada quien pueda observarse a sí mismo y descubrir las maneras sociales y culturales de producción de diferencia.

Cada uno de los modelos presentados tiene su historia, sustento y justificación. Su implementación y su recorrido pedagógico son los que han empezado a redefinir nuevas rutas en este modo de comprender y tramitar lo intercultural en materia educativa. Sin embargo, y a pesar de las virtudes o falencias de estos modelos, lo cierto es que si intentáramos hacer un balance somero de lo que la escuela ha hecho con la diferencia, podríamos referenciar lo siguiente: reproducir desigualdades, fomentar la competitividad y el racismo, discriminar y excluir, desconocer saberes "otros" y privilegiar conocimientos ilustrados y racionales, contribuir a la colonización de las mentes, y esencializar la "otredad", ubicando lo diferente en el lugar de lo exótico y de lo "anormal", pero en transición hacia la modernidad. Una de las razones es que

9 A nivel filosófico esta debe a la vez asegurar una versión personal de la cultura fundamentada en el pluralismo, pero también, una versión colectiva de una síntesis pluralista de la historia de diferencias y de similitudes relativas a las identidades nacionales (traducción libre de las autoras) 
Tabla 1 Modelos de escolarización para tramitar la diferencia cultural

\begin{tabular}{|c|c|c|c|}
\hline Asimilacionista & Integracionista & Multiculturalista & Interculturalista \\
\hline $\begin{array}{l}\text { Promueve proce- } \\
\text { sos de identidad } \\
\text { nacional, civili- } \\
\text { zación y norma- } \\
\text { lización de los } \\
\text { estudiantes por } \\
\text { medio de una edu- } \\
\text { cación homogénea } \\
\text { y masiva que se } \\
\text { traduce en una } \\
\text { escuela que ofrece } \\
\text { cursos de inclu- } \\
\text { sión, adaptación, } \\
\text { lengua y cultura } \\
\text { predominante. }\end{array}$ & $\begin{array}{l}\text { En la escuela se } \\
\text { promueve la inte- } \\
\text { gración de aportes } \\
\text { culturales a una } \\
\text { cultura en común, } \\
\text { se favorece una } \\
\text { participación equi- } \\
\text { tativa y se promue- } \\
\text { ve la cohabitación } \\
\text { entre diferentes } \\
\text { grupos culturales } \\
\text { aunque se crea en } \\
\text { los estudiantes un } \\
\text { sentimiento posi- } \\
\text { tivo de la unidad } \\
\text { nacional. }\end{array}$ & $\begin{array}{l}\text { En la escuela } \\
\text { multicultural se } \\
\text { promueve tanto } \\
\text { el proceso de } \\
\text { asimilación como } \\
\text { la inclusión en } \\
\text { el currículo de } \\
\text { contenidos antirra- } \\
\text { cistas, antisexistas, } \\
\text { etc. Parte de una } \\
\text { reflexión sobre } \\
\text { las minorías en } \\
\text { las escuelas y una } \\
\text { expresión conflicti- } \\
\text { va de las distan- } \\
\text { cias entre cultura } \\
\text { escolar y cultura } \\
\text { regional o local. }\end{array}$ & $\begin{array}{l}\text { La noción de inter- } \\
\text { culturalidad, ade- } \\
\text { más de expresar } \\
\text { la cohesión étnica } \\
\text { de un grupo social } \\
\text { proporcionando } \\
\text { condiciones para } \\
\text { el fortalecimiento } \\
\text { de la identidad } \\
\text { cultural, estimula } \\
\text { la adquisición } \\
\text { de conocimiento } \\
\text { cultural de otros } \\
\text { pueblos. }\end{array}$ \\
\hline
\end{tabular}

la construcción de estos enfoques ha estado alejada de los grandes debates políticos sobre la educación. En ese sentido, si bien se ha avanzado en la idea de conceptualizar algunos asuntos pedagógicos y curriculares, los grandes problemas que subyacen a la interculturalidad, como es el caso de la xenofobia, el racismo y la discriminación lingüística, no han sido encarados de forma estructural.

Ahora bien, la propuesta intercultural, que pareciera ser una vía efectiva de reconocimiento del "otro", un modo de desheredarse del etnocentrismo y abrirse a la valoración de conocimientos ancestrales propios, está aún pendiente, y en ese sentido constituye una utopía para la educación en su conjunto y para la escuela como invención moderna, en singular. Es notorio que los modelos a los que nos hemos referido "pretenden" afectar los modos de funcionamiento de un viejo y legítimo dispositivo de saber-poder como la institución escolar. En ese sentido, la pregunta que ha venido surgiendo de diferentes geografías y contextos culturales es si el reto de interculturalizar la escuela es menos probable que la configuración de un nuevo aparato educador capaz de asumir las tareas de un mundo globalizado pero tensionado internamente por el trámite de sus diversidades 
desiguales. América Latina convive con doscientos millones de indígenas y afrodescendientes; cerca de la mitad de esta población corresponde a niños, niñas y adolescentes menores de dieciocho años. Los indicadores de pobreza, desempleo y analfabetismo se concentran en estos grupos, lo que revela un serio problema con relación a la manera como las naciones y sus Estados tramitan los derechos de estas comunidades y culturas.

\section{Etnoeducación y educación propia. La interculturalidad en el caso colombiano}

La siguiente reflexión busca dar cuenta de los tránsitos que en el contexto colombiano ha tenido el fenómeno de la educación intercultural, destacando que se trata de un recorrido en el cual han estado en juego no solo los "modelos globales" concebidos para tramitar la diversidad y la diferencia cultural, sino una larga historia educativa en la cual estos rasgos de la alteridad étnica han estado presentes bien sea como objeto de invisibilización, de estigmatización, de subalternización o de reconocimiento positivo, en épocas más recientes.

La emergencia de la multiculturalidad educativa de mediados de los años noventa del siglo XX en Colombia está antecedida al menos por dos fenómenos cuya naturaleza y desenvolvimiento permiten comprender la suerte que la diferencia, la multiculturalidad y la interculturalidad tendrán en el escenario de la política educativa colombiana. De una parte, la configuración de la educación nacional como un horizonte pedagógico y político que agenció durante la primera mitad del pasado siglo un modelo de "cultura nacional", y por otra, la emergencia del proyecto educativo del movimiento indígena durante los años setenta. Estos dos acontecimientos producen un "entorno" sin el cual es incompresible el devenir que la idea de interculturalidad tomará en el ámbito de la educación colombiana y de sus políticas públicas.

\section{Una educación nacional, una identidad nacional}

La creencia en la degeneración física, intelectual y moral de las masas llevó a la formulación de una Escuela Defensiva que a partir de prácticas de higienización de la población apuntaba a la moralización y vigorización de la raza. (Sáenz, 2010, p. 112) 
Durante la primera etapa del siglo XX, los procesos de escolarización de la población apuntaban de manera estratégica a la construcción de una identidad nacional (Álvarez, 2007; Herrera, Pinilla y Suaza, 2003; Sáenz, 1992). Esta idea de lo "nacional" se concibió bajo parámetros raciales, culturales y de clase, hecho por el cual no todos los habitantes fueron incluidos en esta contabilidad del reconocimiento; tal fue el caso de indios y negros. En ese sentido la escuela moderna actuó como plataforma para el desarrollo del proyecto de una nación mestiza, y promovió a través de sus políticas del conocimiento un modelo de inferiorización de unas poblaciones y de superioridad de otras. Como lo han resaltado Herrera, Pinilla y Suaza (2003) en sus estudios sobre los manuales escolares de Ciencias Sociales para el período de 1900 a 1950, estos materiales hicieron con sus narrativas e iconografías de la teoría de la superioridad de la raza, un saber escolarizado según el cual "lo blanco europeo se encuentra por encima de los mestizos y estos, a su vez, en un nivel superior al que ocupan los indígenas y los negros", es decir una teoría del "hombre nacional".

Estas imágenes y representaciones de la diferencia cultural, según las cuales lo indígena y lo afrodescendiente, se asocia con lo salvaje, lo periférico y lo atrasado, tendrán un enorme peso en las políticas y normatividades educativas del siglo $\mathrm{XX}$, ocupadas fundamentalmente de consolidar un proyecto nacional, monocultural. De esta manera, los planes educativos del siglo XX dejaron por fuera a las poblaciones étnicas, y se concentraron en expandir un sistema educativo nacional oficial directamente regulado por el Ministerio de Educación Nacional, e interesado en promover un proyecto de cultura nacional. Por esta razón, las políticas educativas dejaron el asunto de las poblaciones negras e indígenas en manos de la iglesia docente, logrando que con el tiempo fuese legítima la discriminación y subordinación de la alteridad, como enfoque educativo. (Castillo y Caicedo, 2008, p. 16)

Este proceso de escolarización sirvió como medio para configurar una identidad nacional prescrita, es decir concebida como algo que se moldea en el pueblo, como un sentimiento que se siembra en el alma de las gentes. Esta "identidad nacional" enalteció ciertos ideales de persona, ciertos valores y creencias, y de otra parte, excluyó y desvalorizó 
otros. Lo nacional gravitó en torno a la representación de lo letrado y católico, y se equiparó a una serie de representaciones que contenían culturas, geografías y poblaciones claramente diferenciadas y jerarquizadas. Como lo ha mostrado Álvarez, en su análisis sobre este período:

[...] desde 1930 el asunto tuvo que ver más claramente con la necesidad de formar una conciencia nacional, lo cual exigía una estrategia mucho más compleja, que pasó por la escuela, pero fue mucho más allá de ella. La mirada se centró entonces en el pueblo, en el alma nacional, en la cultura popular, como una condición para movilizar todos los recursos posibles hacia la consolidación del Estado-nación, lo cual suponía también una economía nacional. La población se convirtió desde entonces en un factor estratégico que debía ser incorporada a los circuitos económicos que la reforma nacionalista iba a crear. (Álvarez 2010, p. 115)

Este modelo de educación nacional se mantuvo vigente hasta finales del siglo $\mathrm{XX}, \mathrm{y}$ a pesar de las reformas implantadas durante las décadas siguientes, lo sustancial del enfoque se expresó de manera concreta en los manuales escolares, los contenidos de los planes de estudio, las formas de cultura escolar vigentes y los propios programas de formación docente de escuelas normales y universidades. Sin lugar a dudas podemos afirmar que la idea de una sociedad diversa y diferenciada cultural o racialmente no fue objeto de ninguno de los modelos que sirvieron para solidificar el sistema escolar colombiano. Muy por el contrario, con el paso del tiempo se fueron naturalizando en el mundo de los saberes escolares algunos estereotipos sobre las poblaciones no nacionales, como en el caso de indígenas, comunidades negras y habitantes de los llamados territorios nacionales ${ }^{10}$.

En ese sentido, los referentes para pensar la educación desde un punto de vista del pluralismo cultural o la diversidad estuvieron ausentes hasta 1991, cuando la Constitución Política reconoció el carácter multiétnico de la nación colombiana, y posteriormente, en 1994, se promulgó la Ley General de Educación,

10 Las investigaciones de Castillo (2010), Mena (2006) y Soler (2009) evidencian que los saberes escolares promovidos por medio de los textos escolares producen una invisibilización y/o estereotipación de lo afrodescendiente y lo indígena. Estos estudios resaltan la circulación de representaciones estereotipadas que circulan en estos materiales de enseñanza, y que en su condición de saberes oficiales mantienen imágenes fijas y reducidas de la gente indígena, negra, palenquera, raizal y/o afrocolombiana. 
que incluyó por primera vez la noción de interculturalidad, como veremos más adelante.

\section{La educación intercultural es educación indígena}

Como en el resto de América Latina, la educación intercultural hace su arribo al país a finales de los años ochenta del siglo pasado, por cuenta de dos acontecimientos: en primer lugar, los proyectos políticos de las organizaciones indígenas, y en segundo lugar la incidencia del grupo de etnoeducación del Ministerio de Educación Nacional durante el período 1982-1992.

En el plano de las luchas de los pueblos indígenas en Colombia, desde la década de los años setenta estos habían planteado una radical propuesta de creación de escuelas propias y formación de maestros bilingües. Durante la primera década de existencia del Consejo Regional Indígena del Cauca (CRIC), movimiento fundador de estas luchas en Colombia, los fenómenos de represión política que caracterizaron este período hicieron de la recuperación de las tierras y la defensa de los derechos humanos la mayor tarea de líderes y comunidades. Poco a poco lograron crear sus primeras escuelas comunitarias y para los años ochenta ya contaban con un grupo de trabajo muy capacitado en el tema. Es en ese momento en el cual surgen los planteamientos sobre la educación bilingüe y bicultural ${ }^{11}$. Este rasgo es importante para diferenciarlo de otras experiencias de naciones cercanas, en las cuales las ideas sobre la EIB vienen promovidas por organismos internacionales que intervienen en comunidades indígenas. En la experiencia de nuestro país, es el propio movimiento indígena el responsable de proponer inicialmente el tema de la educación bicultural para dar paso, al final de la década de 1980, a la idea de una educación intercultural entendida como una característica de la escuela indígena y de las dinámicas del movimiento.

De este modo, el desenvolvimiento de la educación indígena como agencia de movimientos y organizaciones fue abriendo el debate y la discusión en Colombia sobre las relaciones entre escuela y cultura. La noción de educación bicultural propuesta por el CRIC en su conceptualización sobre la educación indígena es la primera pieza en este complejo camino de configuración de la noción de interculturalidad.

Los objetivos de la Educación bilingüe y bicultural que se busca para nuestras comunidades indígenas son:

11 En comunicación dirigida al Prefecto Apostólico de Tierradentro, la Comunidad del Cabuyo expresa en mayo de 1982 los siguiente: "Positivamente pretendemos dar unos pasos tal como pensamos sobre una Educación Bilingüe Bicultural, que es lo que nos anhela porque el ella buscamos pasos firmes y concretos, obteniendo del deber correspondiente de nuestra cultura". Referencia en Periódico Unidad Indigena 56, mayo de 1982, pp. 6-7, Consejo Regional Indígena del Cauca (CRIC), Popayán. 
Dar una educación de acuerdo a nuestra cultura.

Llevar al niño al correcto uso de su lengua materna y del castellano, en su forma hablada y escrita.

Conseguir que los niños apliquen los conocimientos adquiridos en la escuela a la vida real.

[....] Con esta educación que deseamos impulsar no es que nuestras escuelas sean totalmente diferentes a las oficiales sino que nos ceñimos a nuestra vida real y con esto demostrarle que nosotros los indígenas tenemos capacidad académica. (Periódico Unidad Indígena 39, 1979 , p. 9) $)^{12}$

Durante esta etapa se consolida el equipo de Educación Bilingüe y se construye el enfoque pedagógico, comunitario y político del accionar del CRIC en el ámbito de sus políticas culturales. Aparece también la denominación de lo bicultural en algunos pronunciamientos en los cuales el CRIC aclara el carácter de su proyecto educativo, pero al mismo tiempo va consolidando una idea acerca del currículo y de la pedagogía de sus escuelas comunitarias, que serán la superficie para plantear a finales de esta década unas definiciones sobre la interculturalidad.

En primer lugar, la enseñanza en la escuela ha de ser Bicultural, es decir tendrá en cuenta los elementos de nuestra propia cultura que nos sirvan, y los conocimientos útiles de resto de la sociedad. Al niño se le enseña nuestra verdadera historia, para que al entenderla desempeñe un papel positivo y progresista dentro de nuestra comunidad. En segundo lugar la enseñanza debe de ser Bilingüe. El niño se capacitará para hablar y escribir correctamente su propia lengua y el castellano. (Periódico Unidad Indígena 46, 1981, p. 11. Énfasis en el texto original)

Como lo ha señalado Moya (1998) ${ }^{13}$, para el caso continental lo bicultural se asocia a una visión reducida y funcional de

12 El Periódico Unidad Indígena era el medio impreso de comunicación responsable de difundir las determinaciones y propuestas políticas de las organizaciones indígenas de la época.

13 Moya (1998) plantea: "En una rápida visión histórica diría que el concepto de 'biculturalidad' precedió al de 'interculturalidad'. La biculturalidad es al bilingüismo lo que el haz al envés, y se empleó en los contextos de las primeras etapas de la educación bilingüe transicional o asimilacionista (algunos también la llaman 'asimilista' porque servía para asimilar o integrar al indígena en la llamada 'sociedad mayor')" (p. 109). 
la educación indígena. En el caso del CRIC se trata de una concepción transitoria que estuvo presente durante los primeros años de su experiencia, pero que luego desapareció por sus limitaciones para dar cuenta del proceso en curso.

A través de la búsqueda bibliográfica, de la interlocución con organizaciones no gubernamentales que nos financiaban y dentro de los talleres internos nuestros, llegamos a la conclusión de que el concepto de educación bilingüe-bicultural no arrojaba mayores luces para comprender la complejidad de las relaciones entre lenguas $y$ culturas. (CRIC, 2004, p. 133)

En su desarrollo político el CRIC logró consolidar el Programa de Educación Bilingüe e Intercultural (PEBI), que para finales de los años ochenta contaba con recursos epistémicos, pedagógicos, culturales y políticos muy sólidos, por lo cual lograron ser interlocutores legítimos en el permanente debate con el Ministerio de Educación Nacional. Sus protagonistas de primera línea plantean que "la interculturalidad es el compromiso de todos en un proyecto dirigido por el movimiento indígena" (CRIC, 2004). En esta medida las memorias del proceso de más de tres décadas del PEBI refieren que la interculturalidad ha sido un asunto de constante reflexión y acción, aunque la noción en uso no haya sido siempre esta. Un primer plano de interpretación es el que la define como un rasgo distintivo de las relaciones que históricamente han existido entre indígenas y no indígenas en torno a la construcción y puesta en marcha de los proyectos educativos del CRIC.

El mismo PEBI es en sí un
espacio intercultural de
diálogo entre activistas
indígenas y colaborado-
res no indígenas, y tam-
bién entre el equipo PEBI
y las ONG internaciona-
les que nos financian.
Es decir, el PEBI funciona
como un lugar en donde
se intenta vivenciar la
interculturalidad. (CRIC,
2004, p. 126)

De este modo, los actores del PEBI reconocen relaciones y escenarios interculturales en la dinámica "interna" de su proyecto de educación propia. En un marco más amplio, que involucra al conjunto de la sociedad, el CRIC concibe la interculturalidad como un proyecto político que "va mucho más allá del multiculturalismo" y que implica radicales transformaciones en la estructura societal (CRIC, 2004). De este modo la noción se politiza y es en el contexto de los años noventa, cuando esta perspectiva adquiere significados y sentidos novedosos.

Hoy en día entendemos el concepto de 
interculturalidad como el partir desde el conocimiento de lo propio para ir integrando otros conocimientos de afuera. El ejercicio de la interculturalidad es netamente político, puesto que busca llegar a la creación de condiciones para el establecimiento de relaciones horizontales de diálogo entre diferentes. Es decir, la interculturalidad comprende las relaciones generadas y vivenciadas desde la valoración y respeto por el otro, en la búsqueda de condiciones de igualdad desde las diferencias. (CRIC, 2004, p. 123)

\section{La interculturalidad es etnoeducativa}

Hacia mediados de los años ochenta tuvo lugar en Colombia el Primer Seminario de Etnoeducación, auspiciado por el Ministerio de Educación Nacional. En este contexto se expuso oficialmente el enfoque de etnoeducación, marco bajo el cual se definió a mediados de los años noventa el concepto de interculturalidad como un rasgo propio de este modelo de educación indígena.

La educación (no solo está) ha sido impuesta a las comunidades indígenas, sin tener en cuenta sus características, intereses y necesidades, y sin contar con su participación. En este sentido, los programas educativos no han sido más que instrumentos de dominación y conservación de las estructuras socio-políticas, en detrimento de las mismas comunidades y de su auto-transformación. Como una respuesta a esta situación, el grupo de trabajo del Ministerio de Educación acogió al concepto de ETNODESARROLLO, presentado por Bonfil Batalla en la reunión de expertos sobre etnodesarrollo y etnocidio en América Latina, organizada por Unesco en San José de Costa Rica, en 1981 [...].

De acuerdo con esta concepción, surge una alternativa en el campo educativo que es la ETNOEDUCACION, entendida como "un proceso social permanente, que consiste en la adquisición de conocimientos y valores, y en el desarrollo de habilidades y destrezas, según las necesidades, intereses y aspiraciones de las mismas comunidades, que las capaciten para su autodeterminación". (Bodnar, 1985, pp. 79-83) 
Pocos años después, con la Constitución Política de 1991, se crearon nuevos referentes para pensar la educación como un derecho fundamental en una nación pluriétnica. Fue dentro de este marco legislativo que se formuló la Ley General de Educación de 1994, en la cual se estableció que la educación para los grupos étnicos es la etnoeducación. Posteriormente, como la han planteado Castillo y Caicedo (2007), con la promulgación del Decreto 804 en 1995, se estableció la interculturalidad en el corpus de la normativa educativa colombiana. Con esta reforma cobró vida la noción de etnoeducación como parte del servicio educativo que se ofrecía en comunidades y territorios de grupos étnicos. La etnoeducación empezó a incursionar en la arena de las políticas educativas colombianas, y de su brazo surgió entonces, de modo inédito, el concepto de interculturalidad en la redacción de decretos, resoluciones, directivas ministeriales y memorias de eventos del Ministerio de Educación Nacional. Esta idea de la interculturalidad se define como:

[...] la capacidad de conocer la cultura propia y otras culturas que interactúan y se enriquecen de manera dinámica $y$ recíproca, contribuyendo a plasmar en la realidad social una coexistencia en igualdad de condiciones y respeto mutuo. Así las cosas la interculturalidad en Colombia ha estado ligada a la Etnoeducación como política educativa estatal. Aunque pareciera evidente que la Etnoeducación encarna un proyecto intercultural por su condición de "educar en la diferencia," esto no es del todo cierto, debido a que las formas de apropiación y las construcciones de sentido de lo que se entiende por Etnoeducación recogen las trayectorias históricas de organizaciones e individuos posicionados en diferentes lugares políticos, geográficos, ideológicos e institucionales. (Castillo y Caicedo, 2007, p. 32)

En la normativa producida a partir de 1994 la interculturalidad quedó localizada en el terreno de la Etnoeducación de forma casi definitiva. Poco a poco la idea de la interculturalidad se configuró en su descripción como un rasgo constitutivo de las educaciones étnicas (indígena, afrocolombiana, palenquera, raizal y rom) y básicamente en dos dimensiones: 1. Como capacidad de los sujetos étnicos para interactuar con otras culturas; 2 . Como cualidad de los sujetos y los saberes etnoeducativos (Castillo y Caicedo 2007, p. 29). De esta manera la interculturalidad esencializó una mirada sobre las personas portadoras de la diferencia étnica y cultural, es decir, los 
interculturales son los Otros, en tanto sujetos marcados por una condición de diferencia cultural, racial y/o étnica.

\section{La interculturalidad en el currículo. La Cátedra de Estudios Afrocolombianos}

Durante el proceso de la reforma constitucional de 1991 tuvo lugar un evento que debe ser mencionado en este apartado, pues su naturaleza política sirve para comprender el trámite diferenciado que ha operado en materia pública con respecto a los llamados grupos étnicos, bien sean indígenas o afrodescendientes en cada caso. Al terminar su período de existencia, la Asamblea Nacional Constituyente de 1991 tuvo que resolver algunos aspectos que quedaron sin legislar en la corporación. Uno de estos temas fue el referido al reconocimiento de las comunidades negras como etnias de la nación colombiana. Como lo ha señalado Arocha (1993), la etnicidad de estas poblaciones en lo referente a su reconocimiento jurídico está afectada por la larga tradición amerindia de la antropología nacional y de las relaciones del Estado nacional con sus culturas de la alteridad.

Por esta razón se expidió un artículo transitorio, que luego en su cumplimiento dio origen a la Ley 70 de 1993 por medio de la cual se reconocen los derechos de estas poblaciones. En el marco de esta norma y como resultado de viejas luchas antirracistas por parte de organizaciones e intelectuales negros, se promovió la creación de la Cátedra de Estudios Afrocolombianos (CEA), como un mecanismo para erradicar el racismo y la invisibilidad producidos en el sistema educativo nacional ${ }^{14}$. La CEA surgió como un mecanismo curricular de "saberes escolares" basados en la historia y las culturas afrodescendientes en Colombia con el fin de que todos los estudiantes, independientemente de su condición racial, cultural y/o étnica conozcan estos legados. Para lograr tal fin, en 1998 se expidió el Decreto 1122,

\footnotetext{
14 Esta normativa, derivada de la reglamentación de la Ley 70 o de Comunidades Negras de 1993, establece el carácter obligatorio de la CEA en todos los establecimientos educativos de la educación básica y media en Colombia y determina que su ámbito de aplicación opera en el grupo de "áreas obligatorias y fundamentales establecidas en el artículo $23^{\circ}$ de la Ley 115 de 1994, correspondiente a Ciencias sociales, historia, geografía, Constitución Política y democracia" (Decreto 1122, Artículo $2^{\circ}$ ). Igualmente en 2001, el Ministerio de Educación Nacional publica un documento de lineamientos curriculares para la CEA, el cual es resultado del trabajo de un equipo de líderes afrocolombianos, quienes diseñan una propuesta conceptual y pedagógica para este nuevo campo del saber escolar (Ministerio de Educación Nacional, Decreto 1122 de 1998. Serie Lineamientos Curriculares. Cátedra de Estudios Afrocolombianos).
} 
por medio del cual se determina que el sistema escolar de la básica y la media debe incluir en el área de las Ciencias Sociales los contenidos de la CEA. Aunque el magisterio del país no estaba formado para esta nueva tarea pedagógica, su emergencia en el conjunto de las políticas de conocimiento oficial es muy importante y recoge las viejas propuestas planteadas en 1971 por don Manuel Zapata Olivella, quien en el contexto del Primer Congreso de las Culturas Negras de América celebrado en Cali, propuso:

[...] que oficialmente se incorpore la enseñanza de la Historia de África en la escuela primaria y secundaria, a la par de que se exija por parte de los profesores un mayor análisis del significado de la presencia negra en nuestra comunidad a través del proceso histórico desde su arribo e integración en la vida económica, social y cultural. (Zapata Olivella 1988, pp. 19-21)

El surgimiento de la Cátedra de Estudios Afrocolombianos es un hecho inédito en el continente para el momento de su aparición y reviste especial importancia en este debate sobre la interculturalidad en la educación colombiana, por tratarse de la primera incidencia en materia curricular de corte "intercultural" que promueve un movimiento étnico, en este caso el de las organizaciones afrocolombianas. Si bien es cierto que la implementación de la CEA ha sufrido un lento proceso de marginalidad frente a las políticas neoliberales de competencias y pruebas censales, la insistencia de los activistas y del movimiento afrodescendiente en Colombia durante estas dos décadas ha permitido algunos logros simbólicamente destacables, sobre todo en ciudades como Bogotá, donde día a día crece y se tensiona aún más la vida en aulas multiculturales.

La inserción de la CEA en el terreno de las políticas educativas se diferencia del terreno de la etnoeducación en la medida en que esta se plantea como un horizonte de conocimientos para todo el conjunto de la población escolar colombiana, y no solo para los sujetos de la diferencia étnica, es decir de los y las afrodescendientes.

\section{¿A quién le interesa una educación intercultural?}

El discurso programático de la interculturalidad, a diferencia del discurso multiculturalista, tiene vacíos importantes que dificultan la implementación de políticas interculturales. Se desarrolla preferencialmente en referencia a los proyectos de educación bilingüe en áreas geográficas mayormente indígenas de preferencia monolingües. Esto ha conducido a la ruralización de la agenda cultural. Como consecuencia de ello los problemas interculturales 
que -como resultados de los flujos migratorios se concentran en los escenarios urbanos marginales de las grandes ciudades latinoamericanas-, no están siendo atendidos ni considerados en la agenda de las propuestas interculturales (Tubino, 2002).

Podemos afirmar que el conjunto de políticas agenciadas desde finales del siglo XX en países como México, Colombia, Ecuador, Perú e incluso Bolivia, ha estado supeditado a los imperativos de las agendas educativas continentales que diseñan organismos multilaterales como el Fondo Monetario Internacional (FMI) y el Banco Mundial, con lo cual el asunto de la EIB o la interculturalidad educativa ha quedado rezagado frente a los saldos pendientes en materia de cobertura y calidad para cerca de un $20 \%$ de la población que aún no recibe los beneficios de los sistemas escolares oficiales. De este modo lo "intercultural" no forma parte de las grandes prioridades en las políticas educativas, ni siquiera en los países con mayores porcentajes de población étnica, como México o Brasil. Pero este hecho tiene una larga data en la historia de la educación de la región y de Colombia. Como lo plantea Tubino (2002), salvo algunas excepciones provenientes de iniciativas ligadas a proyectos de educación bilingüe con poblaciones indígenas, la educación pública "en América Latina no ha sido multicultural, tampoco intercultural", esto quiere decir que su trámite en el plano de la educación como derecho sigue pendiente en el continente, agravando las condiciones de posibilidad de contar con sociedades no racistas, no discriminadoras ni xenofóbicas en una región en la cual más del $30 \%$ de sus pobladores son indígenas o afrodescendientes.

Debido a que lo intercultural no forma parte de la educación pública y sus actuales afanes de calidad, cobertura y pertinencia, las comunidades y los pueblos cuyos proyectos se sostienen de manera importante en este enfoque enfrentan claras desventajas de ser tratados como proyectos educativos importantes y de lograr que sus demandas sean parte esencial de la llamada educación nacional. En consecuencia, se trata de educaciones de segundo orden en materia financiera, de sistemas de información, de infraestructura y de vinculación docente. Como lo ha planteado insistentemente en sus trabajos Héctor Muñoz: "la interculturalidad constituye una noción ajena y distante a los lenguajes de la educación pública que se instalaron en el continente desde mediados del siglo XX". Por esta razón, la transitoriedad de la multiculturalidad a la interculturalidad de la que 
habla Tubino, en el caso colombiano no se cumple en la medida en que estamos atrapados en el multiculturalismo compensatorio que propone acceso a un modelo educativo homogéneo y monocultural, y detiene de esta manera las posibilidades reales de lograr transformaciones en el sistema escolar. Así las cosas, sabemos que lo que tenemos en materia de interculturalidad, mucho o poco, se debe sobre todo a las batallas que en el terreno educativo han adelantado las organizaciones étnicas de América Latina (indígenas y afrodescendientes).

Un elemento bastante crítico en este panorama se concentra en el fenómeno de invisibilidad de las comunidades y las culturas afrodescendientes en el debate intercultural del continente, cuando estas abarcan más del $25 \%$ del total poblacional (600 millones). Cabe entonces preguntarse ipor qué no son mencionados a la hora de hablar de interculturalidad? Seguramente parte de la respuesta a esta interrogantes reside en las políticas de reconocimiento de la etnicidad producidas desde finales del siglo $X X$, las cuales dieron un lugar privilegiado a lo indígena en contravía a lo afrodescendiente. La mayoría de estudios, investigaciones, congresos y encuentros que se producen en nuestros países en torno a la idea de la educación intercultural o de la interculturalidad en educación, omite, olvida o excluye el abordaje de los procesos, los proyectos y las políticas culturales provenientes de los movimientos y las organizaciones afro en Colombia, Ecuador, Bolivia, Brasil, México y Perú, por nombrar solo las naciones con los mayores porcentajes demográficos de estas poblaciones. En consecuencia, tenemos que reconocer que la interculturalidad se ha forjado en una idea reducida y limitada de lo étnico, a pesar de que en la mayoría de constituciones de América Latina se reconoce este mismo estatus identitario a los pueblos afrodescendientes. Las consecuencias de este fenómeno son claramente expresadas en el terreno de las prácticas racistas que día a día tienen lugar en nuestras escuelas, donde aún hoy persisten y se reproducen prejuicios y estereotipos negativos sobre las personas afrodescendientes.

Finalmente queremos dejar planteado el asunto de la polisemia del concepto de interculturalidad, tanto en su recepción como en sus usos. Como lo sugiere Mateos (2013), la noción de interculturalidad "anida en sus múltiples acepciones, una idea global sobre la diversidad y la diferencia", pues ha migrado internacionalmente, en un movimiento que ha traspasado las fronteras geográficas donde se han postulado sus significados.

Tanto para Colombia como para América Latina la interculturalidad como noción globalizada ha transitado por el asimilacionismo, el integracionismo y el multiculturalismo. La tendencia es que lo intercultural "destaca" la relación que deben establecer las minorías con la mayoría, en el marco del reconocimiento 
de sus derechos y la formulación de políticas educativas. Ahora bien, este énfasis olvida que la llamada sociedad mayoritaria es la que más urgencia de interculturalidad tiene, en la medida en que es en su seno donde se producen y reproducen las formas de discriminación y exclusión hacia las llamadas "minorías".

La "interculturalidad" se ha hecho parte nominal de las políticas de educación de la mayoría de nuestros países, en un claro esfuerzo por asumir el lenguaje multicultural, pero ha mostrado que no tiene mayor eficacia en programas y proyectos concretos de interculturalidad para todos. Como lo plantea Garcés (2007), se reconoce la diversidad existente, vista desde una óptica de la cultura dominante y nacional, pero lejos de la utopía de la intersección, interpenetración o interestructuración positiva de culturas (Manco, 2000). Se trata realmente de un enfoque voluntario y de ajuste, más que de una propuesta de génesis (Demorgon, 2010). A esto hay que sumar el reduccionismo epistémico, que ha confinado en América Latina la idea de lo intercultural a la dimensión de lo étnico, y que lleva a la falsa idea según la cual "los interculturales son los otros", es decir quienes visiblemente representan la diferencia cultural, racial y étnica de la nación (Caicedo y Castillo, 2008).

La perspectiva intercultural producida en los movimientos étnicos, al menos en el caso colombiano, tiene dos rasgos esenciales que la caracterizan en su dimensión política: de una parte, su cuestionamiento a las desigualdades y las exclusiones históricamente presentes entre unas culturas y otras; de otra, en su postura contraria y tensionante al discurso multicultural de la integración en la diversidad. Aún queda mucho trabajo por realizar respecto al análisis de este enfoque intercultural de los movimientos sociales, ya que sus orígenes y recorridos son distintos a los producidos en el mundo académico e incluso al que se ha configurado para las nuevas políticas educativas de la inclusión; sin embargo, en este ámbito residen elementos muy valiosos para comprender lo que está en disputa alrededor de una categoría que se ha vuelto "acomodaticia" para nombrar sin meterse en aprietos los viejos problemas de la discriminación y la exclusión de nuestras sociedades.

A pesar de los distintos orígenes y planos de emergencia, la interculturalidad pareciera ser una noción englobante que sirve para mencionar muchas cosas, todas ellas referidas a los grandes asuntos de la identidad, la etnicidad y el reconocimiento como planos de un mismo horizonte societal idealizado (Mateos, 
2013), en esa medida es obligado recabar en sus maneras de evolución en los diferentes escenarios nacionales e internacionales para revelar las tensiones aún no resueltas, o postergadas bajo este manto discursivo que nombra y celebra la diferencia pero no logra afectar las condiciones de desigualdad social y económica de quienes parecieran ser luz y sombra de la interculturalidad, esos Otros diferenciados, racializados y etnizados durante el largo "siglo de los derechos".

\section{Referencias bibliográficas}

Álvarez Gallego, A. (2010). Formación de nación y educación. Bogotá: Siglo del Hombre.

Bhaba, H. (1994). The location of culture. New York: Routledge .

Bodnar, Y. (1985). Lineamientos Generales de Educación Indígena del Ministerio de Educación Nacional. En, Ministerio de Educación Nacional, Memorias Primer Seminario Nacional de Etnoeducación (pp. 78-85). Bogotá.

Castillo, E. (2011, enero-junio). La letra con raza entra. Racismo, textos escolares y escritura pedagógica afrocolombiana. En Revista Pedagogía y Saberes 34,

Castillo, E. \& Caicedo, J. A. (2008). La educación intercultural bilingüe. El caso colombiano. Colección Libros Foro Latinoamericano de Políticas Educativas - Flape 22. Buenos Aires:
Fundación Laboratorio de Políticas Públicas.

Castillo, E. y Rojas, A. (2005). Educar a los Otros, Estado, políticas educativas y diferencia cultural en Colombia. Popayán: Universidad del Cauca.

Consejo Regional Indígena del Cauca. (2004). Consejo Regional Indígena Del Cauca - CRIC, ¿Qué pasaría si la escuela...? 30 años de construcción de una educación propia. Programa de Educación Bilingüe e Intercultural, CRIC. Bogotá: El Fuego Azul.

Demorgon, J. (2010). Complexité des cultures et de l'interculturel. Paris: Anthropos.

De Sousa Santos, B. (2010). Para descolonizar el Occidente. Recuperado de: http://www.cecies.org/imagenes/edicion_306. pdf

Duschatzky, S. y Skliar, C. (2001). Habitantes de Babel. Políticas y poéticas de la diferencia. España: Alertes.

Dussel, E. (2005). Transmodernidad e interculturalidad. Interpretación desde la Filosofía de la Liberación. México: UAM.

Fernández J. y Muñoz, A. (1998). Ejes de debate y propuestas de acción para una pedagogía intercultural. Revista Iberoamericana de Educación, 17, 207-247.

Fleuri, R. (2006). Intercultura y educación. Revista Astrolabio. Centro de Estudios Avanzados de la Universidad de Córdoba. Recuperado de: http://www. 
astrolabio.unc.edu.ar/articulos/multiculturalismo/articulos/ fleuri.php

Garcés, F. (2007). Las políticas del conocimiento y la colonialidad lingüística y epistémica. En, S. Castro-Gómez, y R. Grosfoguel. (comp.). El giro decolonial: reflexiones para una diversidad epistémica más allá del capitalismo global. Bogotá: Siglo del Hombre/Universidad Central/Instituto de Estudios Sociales Contemporáneos/Pontificia Universidad Javeriana/Instituto Pensar.

García, J.; Pulido, R. y Montes, A. (1998). La educación multicultural y el concepto de cultura. Revista Iberoamericana de Educación, 17, 223-256.

Hall, S. y Du Gay, P. (comps.) (2003). Cuestiones de identidad cultural. Buenos Aires: Amorrortu.

Herrera, M. C.; Pinilla, A. y Suaza, L. M. (2003). La identidad nacional en los textos escolares de Ciencias Sociales. Colombia 1900-1950. Bogotá: Universidad Pedagógica Nacional.

Manco, A. (2000). Compétence interculturelles et stratégies identitaries. Agora débats jeunesses 22, 49-60.

Mateos, S. (2013). La migración transnacional del discurso intercultural. Su incorporación, apropiación y resignificación por actores educativos en Veracruz, México. Quito: Abya-Yala, Universidad Politécnica Salesiana.

Mena, M. I. (2006). La historia de las personas afrocolombianas a partir de las ilustraciones contenidas en los textos de Ciencias Sociales para la Educación Básica. Revista Enunciación, 11, 46-58.

Mena, P. (2008). Educación intercultural. Una historia que se repite. En, G. C. Marras y R. Badini (Eds.). Intrecci di culture. Marginalità ed egemonia in America Latina e Mediterraneo. Roma: Meltemi.

Meunier, O. (2007). Approches Interculturelles en Éducation. Étude comparative internationale. France: Institut National de Recherche Pédagogique. Service de Veille Scientifique et Technologique. Les Dossiers de la Veille. Recuperado en: http://www.inrp.fr/vst.

Moya, R. (1998, mayo-agosto). Reformas educativas e interculturalidad en América Latina. Revista Iberoamericana de Educación OEl, 17, 105-187.

Muñoz, H. (2002). Rumbo a la interculturalidad en educación. México: Universidad Autónoma Metropolitana-Iztapalapa, México D. F. Universidad Pedagógica Nacional Unidad 201 
Oaxaca y Universidad Autónoma "Benito Juárez" de Oaxaca.

Rojas, A. (2005). Inclusión social, interculturalidad y educación. ¿Una relación (im)posible? Recuperado en: www.foro-latino. org/flape/foros_virtuales/.../ FV4-Presentacion.pdf

Sáenz, J. (1992). El saber pedagógico en Colombia 1926-1938. Ponencia presentada al Primer Congreso Iberoamericano de Docentes e Investigadores en Historia de la Educación Latinoamericana. Revista Educación y Pedagogía, 8-9.

Soler Castillo, S. (2009). Racismo y discurso en los textos escolares: representación de la diversidad étnica y racial en los textos de Ciencias Sociales en Colombia. En, J. Arocha, (ed.). Nina, cronista de resistencias y disidencias, (pp. 233-265). Bogotá: Centro de Estudios Sociales, Facultad de Ciencias Humanas, Universidad Nacional de Colombia, serie Estudios Afrocolombianos. Tubino, F. (2002). Entre el multiculturalismo y la interculturalidad: más allá de la discriminación positiva. En, N. Fuller (ed.). Interculturalidad y política. Desafíos y posibilidades, (pp. 51-76). Red para el Desarrollo de las Ciencias Sociales del Perú.

Walsh, C. (2001). La interculturalidad en la educación. Ministerio de Educación Lima-Perú.

Walsh C. (2009, 29 de junio). Interculturalidad y (de) colonialidad. Perspectivas críticas y políticas para el siglo XXI. Ponencia presentada durante el Congreso ARIC. Florianópolis, Brasil.

Zambrano, V. (2004). Derechos, pluralismo y diversidad cultural. Bogotá: Universidad Nacional de Colombia.

Zapata Olivella, M. (1998). El congreso de la cultura negra. Nueva era para la identidad de América. Discurso de apertura. En, Primer Congreso de la Cultura Negra de las Américas, (pp. 19-21). Cali: Fundación Colombiana de Investigaciones Folclóricas Unesco. 